American Journal of Applied Sciences 4 (10): 821-827, 2007

ISSN 1546-9239

(C) 2007 Science Publications

\title{
Using GIS for Retail Planning in Jeddah City
}

\author{
Abdulkader A Murad \\ Department of Urban and Regional Planning, Faculty of Environmental Design, King Abdulaziz \\ University, PO Box 80210, Jeddah-21589, Saudi Arabia
}

\begin{abstract}
The aim of this paper was to identify the possibilities of using Geographical Information Systems (GIS) in retail planning field. A spatial database was created for one major retail center called Cornaish center in Jeddah city, Saudi Arabia. The results of the GIS analysis covers three retail planning issues called Proximity to retail center, retail demand characteristics and spatial interaction between retail demand and supply.
\end{abstract}

Keywords: GIS; Retail Planning; Retail Demand; Spatial Interaction

\section{INTRODUCTION}

Identifying the shopping patterns of retail consumers are some of the most complex phenomenon in the business world. The decision of where to shop for what depends on compounded affect of personal product, chain and area preferences coupled with accessibility issues such as road and transit network, parking and access to amenities. The success or failure of a retail establishment depends on knowledge of its prospective and current consumer base. Without such knowledge any attempts at planning what goods and services to offer and how to market the goods and services are expected to have poor effectiveness and failure.

Geographical Information Systems (GIS) are used today at several planning applications studies including land use planning, health care planning, and transportation planning. Retail planning is of the spatial based fields that can benefit from using this novel technology. Retail planners are faced with many issues that can be better handled with GIS. These include constructing demographic, sales and competitive analysis, finding the best locations for new retail stores, creating effective marketing campaigns, scheduling and route deliveries, and providing better customer care and information. This paper is focused on using GIS for some of these related retail assessment issues on a selected retail center called Cornaish center in Jeddah city, Saudi Arabia. In this application, three main issues were selected which are: the distribution of retail demand, characteristics of retail customers, and the spatial interaction of retail demand.

\section{Retail planning}

Overview: The objectives of retail planning can be summarized as the provision of the right amount of land for retailing in the right place, such objectives are influenced by three main issues. These are:

1. The economic hard facts about the profitability of shops in any location, which ultimately sets the limits of what is possible
2. The social function of shopping, either on its own, or as a complement to other activities, and

3. The value of shopping as a ratable asset ${ }^{[1]}$.

Urban and regional planners play important role in the distribution of retail facilities at any built up area. They could draw out plans that encourage local authorities or private developers or a combination of public and private initiative to redevelop existing centers or build new shops. These plans could modify the retail pattern in the form of (a) some extension to central area commercial uses, (b) removal of some central area or other commercial uses because of road proposals, (c) removal of parts of ribbon shopping uses in the inner parts of towns, or (d) provision of the neighborhood centers in existing residential areas ${ }^{[2]}$. In order to prepare such plans urban planners first identify the retail space that is required, or can be supported, by the population, and then distribute the needed retail space within the city. There are two major sets of factors that determine the planning decision on a certain retail development. These are the population and the site factors. The former concerns about population size, growth, composition and purchasing power. On the other hand, the site factor is related to site traffic and accessibility, size of retail activity, and cost of development. Ideally, retail planners should look carefully at these two factors and try to investigate each one of them as well as bringing them together to produce the required analysis which will lead to a specific retail development decision.

One of the major tasks that retail planners should cover is related to the development and the efficient distribution of retail centers at any built-up area. The location of consumers, their numbers, and relative affluence are the starting points in such tasks. 
There are two many analytical techniques that can be used for retail planning and assessment purposes. One of them is known as catchments area analysis. The catchments area is the sphere of influence from which the vast majority of retail sales for a particular center or development are derived ${ }^{[3]}$. The shape and the extent of shopping catchments area is influenced by the size of the center, the proximity of competing centers, the variety of trades provided, the general accessibility, the deficiency in other levels of the shopping hierarchy, the car parking facilities, and the availability of other services. This approach assumes that each retail center sells an undifferentiated product and the consumers will use the closest facility. Such analyses are appropriate when discussing the qualitative (what kinds of people?) aspects rather than the quantitative (how many sales) aspects of the market ${ }^{[4]}$. Accordingly, catchments area analysis discount the market size and ignore the less than perfect penetration rate, in order to permit simple spatial analyses that assumes evenly distributed households and sales. The catchments area can be used as a descriptive method to observe the degree of center coverage, to identify areas of under-representation as obvious gaps in the map, and thus to spit potential new sites. Once the retail center catchments area, or what is known as the "trade area", is delimited in space, the analyst can examine the composition of the market by means of a market profile that shows a break down of the number of households in various income groups, demographic categories, ethnic and racial origins, or life style combinations. The customer profile of any retail center is useful in comparing the actual survey data collected from customers with census data. This method has been used extensively, both by major retailers, and by consulting firms, in order to explore the possibility of future entry into selected market areas. It can be regarded as an elementary form of feasibility analysis, based on aggregate census information plus data on accepted industry norms (such as average sales/square foot) ${ }^{[4]}$.

The catchments are analysis is frequently used in selecting sites for new retail centers and for modeling the evolution of a system of chain locations. A market penetration approach, on the other hand, is more relevant to a single operating retail outlet that which to increase its sales, either by extending its trade area in space or by attracting a greater proportion of households within the existing trade area. One example is found in Birkin et al., $1996^{[5]}$., where the market penetration is found for several UK retailers to identify the centers respective national market shares and the areas of good and poor performance. This type of analysis requires two main kinds of data, which are the customer's list that is allocated to residential areas, and the total number of potential households or customers. Retail planning studies usually collect data about centers customers by sampling sales slips, conducting in-store ruffles, or interviewing customers at such centers. In the later approach customers are usually asked for the address and information concerning their socio-economic status, shopping attitudes and behavior and travel patterns. The customer location data is divided by the total number of households in each residential area to produces a map of market penetration. Usually the market penetration results are highest near the shopping centers and decline irregularly with distance. However, some centers may have different situation where distance is not a big challenge for their customers. The main advantage of this type of analysis is that it can help centers developers to know where are their customers as well as knowing where they should be develop to capture new customers.

Classification of retail centers: There are two basic methods of classifying retail centers, and they are based on either the types of goods and shops included or based on the trade area. In the forms method, retail centers are divided into two groups, those selling convenience goods such as food items and toiletries, and those selling durables, such as clothing, furniture and household appliances. The latter method of retail centers classification produces the following types of centers:

a) Neighborhood Center: The function of neighborhood center is to provide a range of convenience goods and personal services, for the day-to-day needs. The assumed catchments population is 2500 to 40,000 people within a six-minute drive times and it is generally assumed that consumers visit there nearest center ${ }^{[6]}$. The location of neighborhood center should be embedded in residential areas. However, commercial developers prepare sites at intersections on major roads, which are on the edge of residential blocks. The average area for this type of centers is 40,000 to 50,000 square feet ${ }^{[2]}$.

b) Community Center: This type of retail centers offers shoppers greater depth and range of merchandize-assortments in clothing sizes, styles, colors, and prices than does a neighborhood center. The community center serves from 40,000 to 150,000 people, and has a site area of 4-12 ha ${ }^{[6]}$. Community centers have convenience goods more than neighborhood centers, but at the same time they have durable goods less than regional centers. 
c) Regional Center: The third type of retail centers provides all forms of general merchandise, apparel and furniture, and almost all those retail facilities available in the town center. The size of regional centers varies dramatically from 10 acres for a multilevel center to over 100 acres for a large single level center (ibid). These centers comprised a great number and variety of shops selling convenience goods and competing with one another by low prices and range of assortment [6].

GIS uses in retail planning: Geographical Information Systems (GIS) is defined as a system for capturing, storing, checking, manipulating, analyzing and displaying data that are spatially referenced to the earth [7]. Any GIS software should have at least six main modules that are known as data input, data model, data storage, data manipulation, data analysis, and data output module. For example, ArcGIS software that is one of the most used software, is designed to have these modules with different desktop applications known as ArcCataloge, ArcMap, ArcGlobe, ArcToolbox, and ModelBuilder. Using these applications users can perform any GIS task, from simple to advanced, including mapping, geographical analysis, data editing and completion, data management, visualization and Geoprocessing ${ }^{[8]}$. In addition to these desktop applications, ArcGIS has many other optional desktop extensions that allow users perform tasks such as raster geoprocessing and three-dimensional analysis. In many cases, users require GIS access through intermediate means- for example, helper applications, focused GIS applications, and mobile devices- as well as through high-end professional GIS desktops or simple Web browsers connected to Internet servers ${ }^{[8]}$

There are many fields that can benefit from the application of GIS. One of these fields is the retail planning field. GIS provides advanced analysis tools and complete data package for analyzing retail and demographic information as an aid in making critical retail related decisions. These tolls allows retail users to do the following tasks:

- Choosing retail locations.

- Identifying and reaching potential customers.

- $\quad$ Finding new markets.

- Performing customer or store prospecting.

- Defining customer-based or store trade areas.

- Identifying best retail locations.

- Conducting an analysis of market penetration.
- Creating gravity models to forecast potential sales at new retail locations.

- Performing drive-time analysis over street network.

By combining information such as retail sales data, demographics, and competitor locations, with geographical data, such as census boundaries, territories, or store locations, GIS helps users better understand their market, customers, and competition ${ }^{[8] \text {. }}$ The last decade has witnessed the wide spread adoption of GIS by retail organizations for decision making purposes. For example, Langston et al, $1997^{[9]}$, have applied GIS for studding three major UK grocery retailers (Sainsbury, Kwik, and Asda) and defined the regional market shares of those retailers. Another example of GIS application in retailing is made by Birkin et al, $1996^{[5]}$, , in which GIS is used to analyze market penetration of BMW cars. Murad, $2003{ }^{[10]}$, have made another interested GIS application for two major shopping centers at Saudi Arabia. There are several well-known retailers at Western Europe and northern America that have also adopted GIS including IKEA at Canada, TESCO, Marks \& Spencer, and Boots at the UK ${ }^{[11]}$. The benefits that GIS generate for retailers include having timely access to relevant market information and the ability to manipulate this to better understand the markets and the retailer's performance, and the implications for investment decisions [12]. The diffusion of GIS in retail organizations can be traced to a number of factors relating to supply and demand of retail services. The demand factors include location of retail stores and maximizing profitability. Meanwhile, the supply factors are related to location of competitors and the visualization of consumer behavior. GIS is considered as useful technology at any retail-planning project because it can find answers to questions such as:

-Where to open new store?

-Which stores are under performance?

-What is the market share and penetration?

- How many potential customers live within 10 miles of the store?

-How many competitors are located within the market area of the store? And

-Where should a new store be located in order to minimize the impact it has on the current location of stores?

GIS could provide answers to those questions in the form of market mapping, catchments area identification, consumer profiling and identification, mapping of key performance variables, and the complex modeling of an entire retail network. This paper will address three main retail related questions and will use GIS in answering them. These are: where 
are current customers are located, what is the economical/expenditure backgrounds of retail demand, and what is the possible flow of retail demand to the selected center.

\section{MATERIALS AND METHODS}

In order to use GIS for the selected retail center (Cornaish center), the author has made a survey on 700 retail customers. The purpose of the survey was to build a spatial database for Cornaish center that can be used for defining the location of retail customers and also for finding out their social, economical, and shopping background. All of the collected data were captured and analyzed using ArcGIS-Arcinfo (Version 9) software. This paper will cover some data that were not been explored before about this retail center and they are about consumer mobility (car ownership of retail customers), and about the purposes of customers' visits to Cornaish center. In addition to customers survey data, the present study has collected data about Jeddah city road network that can be used for defining the spatial extent of the city. All of the collected data were in a non-digital formats. Accordingly, manual digitizing was a major step for entering these data into the GIS software. This task is covered at the ArcGIS desktop integrated applications that are ArcCatalog, ArcMap, and ArcToolbox. ArcCatalog is used to find, create, preview, document, and organize geographic data and to create sophisticated geodatabases to store the data. The ArcMap application is used by the present study for all mapping and editing tasks, as well as for map based analysis. Meanwhile, map editing and attributes entry is covered using ArcMap. The third main application, which is the ArcToolbox, is used for data editing and geoprocessing.

\section{RESULTS AND DISCUSSION}

Proximity to retail center: Some of the most successful retailers have joined retail market with new products as they have recognized gaps or niches unfilled by existing major retailers ${ }^{[5]}$. Accordingly, retailers should always monitor their existing trade areas and try to maximize those areas too. The present study has used the collected data about retail customers to define their location and their proximity to Cornaish center. Fig1 defines those customers location and their spatial relation to Cornaish center. In order to define the center's proximity zones, mapping distance function (which is one of ArcGIS spatial analyst software) is used to create a distance raster file that shows the distances around the selected center. This function computes an output raster file where the output value at each location is potentially a function of all cells in the input raster data sets. It measures the distance from each cell to the closest source (for this application, the source is the retail center location).

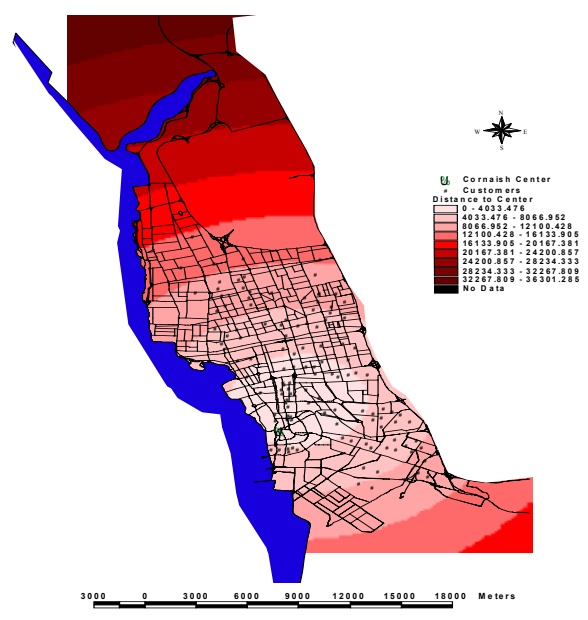

Fig. 1: Proximity to Cornaish center

The results of this function, which are presented at Fig1, indicate that the Jeddah city is divided into accessibility zones based on their proximity to Cornaish center. $90 \%$ of customers come from the first and second proximity zones. This means that the northern parts of Jeddah city (which are more than $8 \mathrm{~km}$ from the retail center) are less attracted to Cornaish center. Accordingly, retail planners of this center should find out why such zones are not bringing good enough customers. This could be achieved by a further study that defines the location of other retail centers in Jeddah and their spatial relationships to Cornaish center.

Retail demand mobility: Identifying the characteristics of retail demand is one of the important tasks at any retail-planning project. This task includes defining the social and economical classification of the desired demand. The performances of retail demand fundamentally influence the way in which the retail network evolves. There are several demand related issues that can be covered in retail planning studies. One of these is called consumer mobility. There is a strong correlation between car ownership rates and income ${ }^{[13]}$. This means data about customers mobility can be used for defining the customers' income. Jones and Simmons, $19900^{[4]}$, have presented an example of how to identify customers' profile of retail of retail demand at the UK. Reference Murad, $2003^{[10]}$, has also discussed how to explore retail demand profile using 
GIS. For example, the spatial distribution of household size of retail customers can be plotted on a GIS map based on points classification methods. This method is simple but useful for classifying retail demand profile. The present study has used another useful GIS technique known as Thiessen polygons. This means that all retail demand locations that are shown at Fig. 1 are transformed into polygon features. This function creates polygons from a set of point features and derived in such away that each polygon represents the catchments area of points, i.e. the area inside the polygon is closer to that point than to any other point ${ }^{[13]}$.

Thiessen polygons are applied for two useful demand data that are car ownership and purposes of customers' visits to the selected center. Defining car ownership of retail demand is considered as useful data because it can help retail planners in understanding the economical background of their retail customers. The results of this data are shown at Fig. 2 and it clear that most of Cornaish center customers (70\%) own only one car and in this case they are representing limited income group.

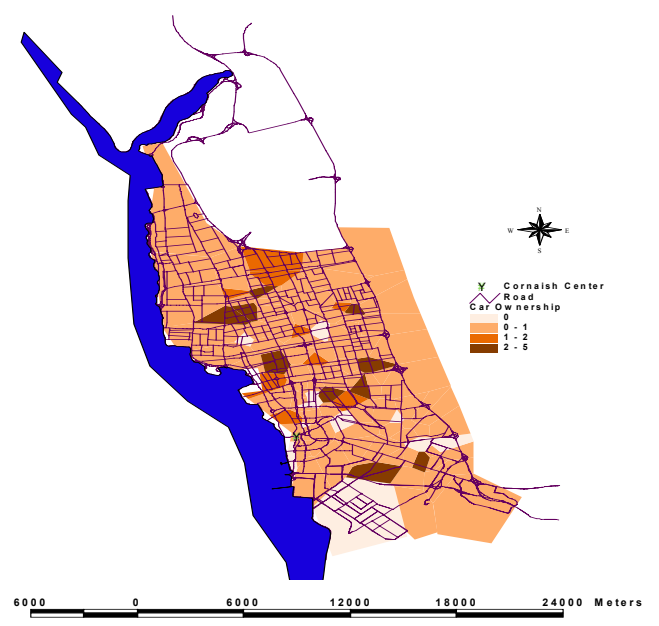

Fig. 2: Car ownership of retail demand

Those customers are spread over all city parts. Based on this finding, retail planners of Cornaish center should make sure that retail products of this center should be suitable to this limited income customers.

urposes of retail demand visits : The second useful data that were covered by this survey refer to purposes of Cornaish center customers visits. These types of data help retail planners in understanding if customers are visiting the center to bay their needed goods or there are other purposes for there visits to this center. Generally, retail demand visit their selected centers for three main purposes which are baying public goods, getting general idea about the center products, or entertaining households children. These purposes were included at the present study's survey. The results of this type of demand data are shown at Fig. 3 that indicate that about $50 \%$ of retail customers come to Cornaish center for entertaining their children at the children play zone which is available at this center. These customers are distributed at all city parts. It is also founded that about $25 \%$ of customers come to Cornaish center to bay their required goods and they are mainly from central and northern city districts. The remaining $25 \%$ of customers (mainly from eastern and central city parts) visit Cornaish center for getting a general idea about its retail products. Based on these results, it can be said that this center needs more marketing at northern and eastern city parts to attract customers for baying public goods from Oases mall.

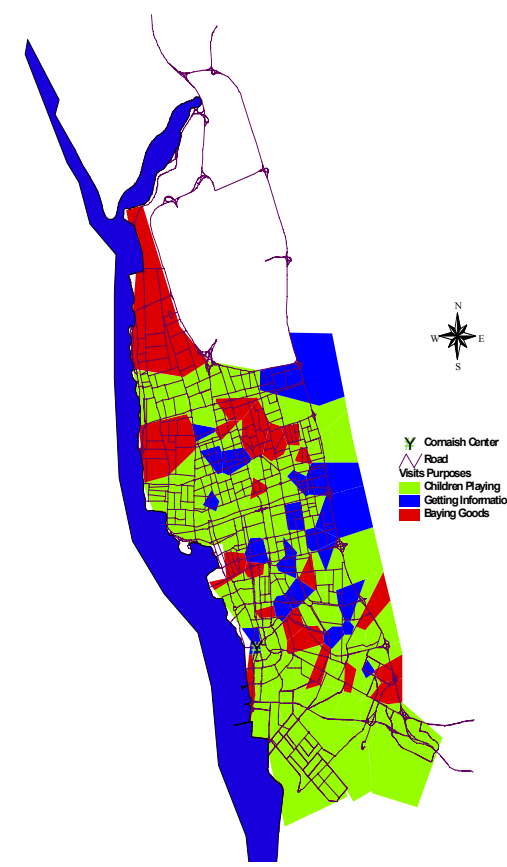

$\begin{array}{llllll}3000 \quad 0 \quad 3000 \quad 6000 & 9000 & 12000 & 15000 & \text { Meters }\end{array}$

Fig. 3: Purposes of retail customers visits

Spatial interaction of retail demand: One way of applying spatial analysis models in retail planning field is by using GIS analysis functions that are built based on certain statistical models. GIS softwares have been developed today to include several spatial analysis functions that can be used for different purposes. This part of the study will discuss the use of spatial interaction models in retail planning field. Versions of 
spatial interaction models are offered at the major market analysis companies in different countries ${ }^{[13]}$. This type of models needs detailed demographis and market research data to evaluate market size and detailed information about competitor charachterstics and store performance data on the suplly side. Spatial interaction is a technique used to compute or predict the number of interactions occuring between two spatially spreaded places. The interaction numbers computed between places can be used in a variety of methods. These include the making of trade-area maps, determining the demand of services, locating a retail store, finding a stransportaion hub to serve a number of places and detremining flows between origins ${ }^{[15]}$. Different studies have applied spatial attraction models to examine flows of people to shopping centers ${ }^{[5]}$ and ${ }^{[10]}$, to schools ${ }^{[16]}$, and to health centers ${ }^{[14]}$. These models allocates flows of expenditure between origin and destination zones on the basis of two main hypothesis:

a- Flows between an origin and destination will be proportional to the relative attractiveness of that destination, and

b- Flows between an origin and destination will be proportional to the relative accessibility of that destination [13].

The origin and destination zones have taken many forms in previous studies. For example, the postal sectors or enumeration districts are used at UK and Europe for defining origin zones. The destinations tend to be individual shops or shopping centers, depending on the application.

Having defining the origin and destination zones, spatial interaction model works on the assumption that in general, when choosing between centers that are equally accessible, shoppers show a performance to the more attractive center (which can be measured by size or other attributes such as parking size, price, etc). When centers are equally attractive, shoppers show a preference for the most accessible center ${ }^{[15]}$.

Spatial interaction models are represented in the following formula:

$$
\begin{aligned}
& \mathrm{S}_{\mathrm{ij}}=\mathrm{A}_{\mathrm{i}} \times \mathrm{Oi} \times \mathrm{W}_{\mathrm{j}} \times \mathrm{f}\left(\mathrm{C}_{\mathrm{ij}}\right) \\
& \text { Where }
\end{aligned}
$$

$\mathrm{S}_{\mathrm{ij}}$ is the flow of peoples from residential area $\mathrm{i}$ to retail center $j$.

$\mathrm{O} i$ is a measure of demand in area $i$,

$\mathrm{W}_{\mathrm{j}}$ is a measure of attractiveness of center $\mathrm{j}$,

$\mathrm{C}_{\mathrm{ij}}$ is a measure of the cost of travel or distance between $i$ and $j$, and

$\mathrm{A}_{\mathrm{i}}$ is a balancing factor.

To calculate spatial interaction there are three certain conditions that must be presented. These are defined as following ${ }^{[15]}$ :

1- Complementarity: It states that for two locations to interact, there must be demand at one location and supply at the other and that the demand and supply must complement each other.

2- Intervening Opportunity: This condition states that for two complementary locations to interact, there must be no intervening opportunity. In other words, intervening opportunity will take away potential interaction between two complementary locations if it can provide the needs of one of the location.

3- Transferability: The third condition of spatial interaction states that for interaction to occur, it must be feasible to transfer the supply to the demand location. It is a measure of the costs involved for the interaction to occur or a measure of the friction of distance evaluated in time and money.

The above three principles are used in computing spatial interaction. The complementarity condition encourages interaction, and transferability and intervening opportunity conditions represent the frictional effects of distance.

ArcGIS-Arcinfo (version9) software provides the spatial interaction function within the Network analysis module. The present study has used this software to model the flows of retail demand to the selected retail center (Cornaish center) at Jeddah city, Saudi Arabia. In this study, $\mathrm{O}_{\mathrm{i}}$ is referred to the number of retail customers at each city district, and $\mathrm{W}_{\mathrm{j}}$ is related to the size of retail center as a measure of center attractiveness. In order to use the interaction function, a point coverage is created showing location of city districts and location of retail center together with attribute data for retail demand and supply. In addition, road network coverage is created for Jeddah city.

The results of this model are shown at Fig. 4 which can be used by retail planners for defining the performance of retail center. In this example, the north and south districts are representing the low demand areas and therefore, residents of such areas need to be attracted to this retail center through some marketing methods that could promote this center to such areas.

This example indicates that spatial analysis models when used with GIS better decisions can be made on any spatial problem that faces urban planners. For example, urban planners can use spatial interaction models to predict demand flows to any type of 
community facilities such as schools or parks and the results of these models can help planners in deciding wither changes in such facilities are worth to be made.

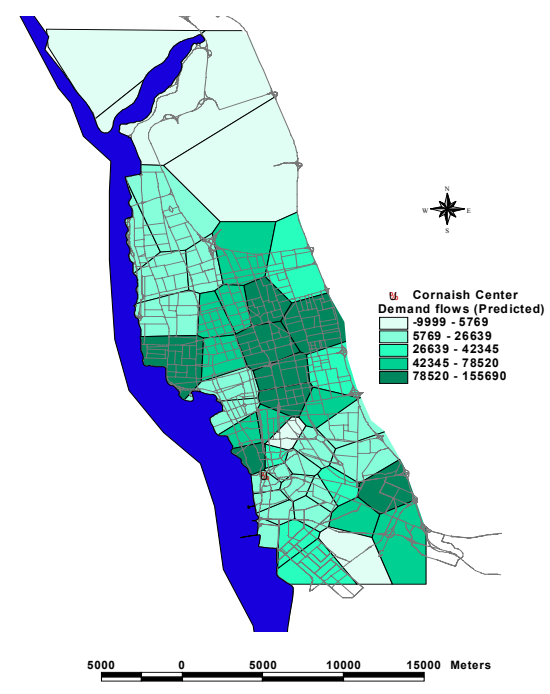

Fig. 1: Predicted customers flows to Cornaish center

\section{CONCLUSION}

Retail planners are faced today with several spatial issues regarding retail demand and supply of any area. These affect the location and the distribution of retail facilities. Most of these issues are related to consumer behavior. They include defining consumer mobility, levels of retail demand expenditure \& income, changing age profiles, changing in household size, population growth and redistribution, and new consumer groups. This paper has selected some of these consumer behavior issues that affect one retail center in Jeddah city called Cornaish center. For this center, GIS is used to study the location of this center in relation with consumer's locations. It is founded that most of customers live close to this center and there are only 10 $\%$ of customers come from far distance districts. In addition, the study has founded that most of the centers customers are from limited income grope because they own only one car. Finally, the study produces a spatial interaction model that allocate demand zones to the selected retail center based the center's attractiveness and based on the cost of travel distance. The main finding of this model is that there are two low demand areas that need to be explored further with a marketing study for Cornaish center. These are located at north and south of Jeddah city.

\section{REFERENCES}

1. Frics P. \& Riba A., 1988, Retail Development, Estates Gazette, London.

2. Guy C., 1980, Retail Location and Relative Planning in Britain, Gower, London

3. Trades D., 1991, Urban Models in Shopping Studies, NEPO, London.

4. Jones K., and Simmons J., 1990, The retail Environment, Routledge, London.

5. Birkin M., Clarke G.P., Clarke M., and Wilson A.G.,1996, Intelligent GIS: Location decisions and strategic planning, Geinformation, Cambridge.

6. Dawson, J, 2000, Retail at century end: some challenges for management and research, International review of retail, distribution and consumer research, 10.(2);119-148.

7. Grimshaw D., 2000, Bringing Geographical Information Systems into Business, Wiley, New York.

8. Ormsby, T., Napoleon, E., Burke, R., Feaster, L., and Groessle, C. (2004) Getting to Know ArcGIS Desktop, ESRI, Redlands.

9. Langston P., Clarke G., and Clarke D., 1997, Retail saturation, retail location and retail competition: an analysis of British food retailing, Environment and Planning A, vol. 29, pp.77-104.

10. Murad A., 2003, Creating a GIS application for retail centers in Jeddah City, International Journal of Applied Earth Observation and Geoinformation, vol.4, No.4, pp. 329-338.

11. Seleight P., 1995, Neighborhood watch geodemographic and lifestyle data in the UK GIS market place, Mapping Awareness, vol.9, No.6, pp. 18-21.

12. Clarke G. and Clarke M., 2001, "Applied spatial interaction modeling" in G.P. Clarke, and M. Madden (eds) Regional Science in Business, Springer, Berlin.

13. Birkin, M., Clarke, G., and Clarke, M. 2002 Retail geography \& intelligent network planning, Wiley, Chichester.

14. Murad A., 2004, Using GIS for predicting demand on retail centers at Jeddah city, Journal of Engineering Sciences, vol.32, No.2, pp. 10051016.

15. ESRI, 1993, Network Analysis, ESRI, Redlands.

16. Murad A, 1998, Application of Geographical Information Systems for Educational Facilities Planning, unpublished PhD Thesis, University of Newcastle upon Tyne UK. 